\title{
The Role of Dispositional Traits in Accounting for Country and Ethnic Group Differences on Adjustment
}

\author{
David Matsumoto, ${ }^{1}$ Sanae Nakagawa, ${ }^{1}$ and Aaron \\ Estrada $^{2}$ \\ ${ }^{1}$ San Francisco State University \\ ${ }^{2}$ University of California, Santa Barbara
}

\begin{abstract}
Country and ethnic group differences on adjustment have been demonstrated numerous times, and the source of these differences has been typically interpreted as cultural. We report two studies in which country (Study 1) and ethnic group (Study 2) differences on depression, anxiety, optimism versus pessimism, well-being, and self-esteem are mediated by dispositional traits. These findings provide an alternative explanation for previously reported country and ethnic group differences on these variables and encourage researchers to consider multiple sources, including traits, in their models and studies.
\end{abstract}

Many country differences have been documented on a host of variables related to adjustment (Diener, Diener, \& Diener, 1995; Group, 1994; Inglehart, 1998; MacIntosh, 1998; Suh, Diener, Oishi, \& Triandis, 1998; Veenhoven, 1993, 2000). For instance, Japanese have higher scores than Americans on depression (Iwata \& Buka, 2002), anxiety (Iwata \& Higuchi, 2000), and negative emotional experiences (Kitayama, Markus, \& Kurokawa, 2000), whereas Americans report higher scores on satisfaction with life (Diener, Diener, et al., 1995; Oishi, Diener, Lucas, \& Suh, 1999), self-esteem (Heine, Lehman, Markus, \& Kitayama, 1999), optimism (Chang \&

We thank Hiroshi Yamada, Satoru Furuya, Juri Homma, Yumi Ishii, and Jamie Louie for their assistance in the data collection and Kemberlee Bonnet, Joanne Chung, Jung Yun Jang, Hyi Sung Hwang, Jessie Wilson, and Caroline Jones for their assistance in the general laboratory program.

Correspondence concerning this article should be addressed to David Matsumoto, Department of Psychology, San Francisco State University, 1600 Holloway Avenue, San Francisco, CA, 94132. E-mail: dm@sfsu.edu.

Journal of Personality 77:1, February 2009

(C) 2008, Copyright the Authors

Journal compilation (C) 2009, Wiley Periodicals, Inc.

DOI: $10.1111 / \mathrm{j} .1467-6494.2008 .00542 . x$ 
Asakawa, 2003; Chang, Asakawa, \& Sanna, 2001; Heine \& Lehman, 1995), and positive emotional experiences (Kitayama et al., 2000). Theories that account for these differences typically focus on the possible role of self-construals and worldviews (Heine \& Norenzayan, 2006; Kitayama, Mesquita, \& Karasawa, 2006), suggesting that country and ethnic group differences occur because of different self-construals produced in different cultures (Markus \& Kitayama, 1991). For example, Iwata and Higuchi interpreted American-Japanese differences in anxiety as occurring because, in Japan, psychological well-being is subordinate to the well-being of the group, that the inhibition of positive affect is a moral distinction, and that the Japanese seem less likely to generate positive feelings.

But there are many potential sources of country differences in adjustment (Matsumoto, 2007). One problem plaguing this area of research is that researchers typically compare data from countries (or ethnicities) in quasi-experimental designs without the operationalization and empirical linkage of variables theoretically hypothesized to account for those differences (Matsumoto \& Yoo, 2006). Such designs treat country or ethnicity as proxies for culture, and cultural mechanisms are generally invoked post hoc to explain observed differences. This problem is exacerbated because, with only a few exceptions (Diener, Diener, et al., 1995; Oishi et al., 1999), many studies compare only two groups, such as Americans versus Japanese or European Americans versus Asian Americans, and in reality there are many differences between any two groups that could account for the differences between them.

One source of the country differences in adjustment not considered until now is dispositional traits. There is, in fact, considerable evidence indicating a reliable relationship between the five-factor model of traits (Openness, Conscientiousness, Extraversion, Agreeableness, and Neuroticism; McCrae \& Costa, 1999) and adjustment. Early research in this area demonstrated moderate to strong relationships between well-being and Extraversion and Neuroticism (Costa \& McCrae, 1980; Heady \& Wearing, 1989; Lucas \& Fujita, 2000; Watson \& Clark, 1992), with the former related to life satisfaction, happiness, and positive affect and the latter related to negative affect (DeNeve \& Cooper, 1998). More recent studies have replicated these findings (Diener \& Lucas, 1999; Schimmack, Oishi, \& Furr, 2004; Schimmack, Radhakrishnan, Oishi, \& Dzokoto, 2002) but have shown that other traits are also related 
to well-being and adjustment (DeNeve \& Cooper, 1998; McCrae \& Costa, 1991). For example, Robins, Tracy, Trzesniewski, Potter, and Gosling (2001) examined the relationship between self-esteem and the Big Five personality dimensions on a sample of 326,641 individuals who participated in an online study. The five dimensions cumulatively accounted for about $34 \%$ of the variance of self-esteem, and this finding was robust across different age groups, gender, social class, ethnicity, and nationality. Kwan, Bond, and Singelis (1997) showed an association between traits and the Rosenberg Self-Esteem scale in both American and Hong Kong Chinese college students. Kling, Ryff, and Love (2003) found that Extraversion and Openness predicted self-esteem and Neuroticism and Openness predicted depression.

Different theories have been proffered to account for withincountry, individual-level relationships between traits and adjustment. They typically focus on the possible influence of different aspects of temperament on individual differences in well-being and can be generally organized around three psychological processes: baseline levels of cognitive and affective well-being, emotional reactivity, and cognitive processing of emotional information (Diener, Oishi, \& Lucas, 2003). Individuals high on Extraversion and low on Neuroticism, for instance, may come to the world with uniquely higher baseline levels of well-being and happiness, they may be more reactive to positive events or stimuli and relatively less reactive to negative ones, or they may be more likely to perceive and remember positive events compared to negative ones. These possibilities have led some researchers to argue for a set-point theory of life satisfaction and well-being (Eid \& Diener, 2004; Lykken \& Tellegen, 1996), although recent research suggests that it is a "soft" baseline that allows for fluctuation over the life course (Fujita \& Diener, 2005).

\section{Accounting for Country and Ethnic Group Differences in Adjustment and Well-Being With Dispositional Traits}

Recent research involving the NEO-Personality Inventory Revised (NEO-PI-R; Costa \& McCrae, 1992), a measure of the Five Factor Model, has demonstrated reliable cross-country differences in aggregate levels of traits (Allik \& McCrae, 2004; McCrae, 2002; McCrae, Terracciano, Khoury, et al., 2005; McCrae, Terracciano, Leibovich, et al., 2005). Japanese, for instance, score higher on 
Neuroticism, whereas Americans score higher on Extraversion and Conscientiousness (Matsumoto, 2006b; McCrae, 2002). Countrylevel differences in mean levels of traits may occur for several reasons. For instance, those differences may result from sampling biases or scalar inequivalence. There is, however, a considerable amount of evidence of construct validity for country-level scores to make this an unlikely possibility (McCrae \& Costa, in press). It may be that different environments exert different cultural presses for the shaping of different trait levels that are most adaptive in those environments, producing country differences in means. Country differences may also reflect differences in the frequency of trait-related alleles in different populations. Countries exist in different geographic locations, and differences in trait-related genes may occur because of ancestral migration, genetic drift, or even natural selection (Allik \& McCrae, 2002). Finally, some combination of these factors may explain the differences.

If differences in aggregate levels of dispositional traits exist on the country level (regardless of their source), and if individual differences in traits account for adjustment within countries, then country differences on aggregate levels of the dispositional traits may account for country differences on adjustment. That is, if Country A has a larger number of extroverts than Country B (regardless of how that came to be), and if extraversion has been shown to be positively related to adjustment, then one would expect that Country A would have higher mean levels of adjustment than Country B. Conversely, if Country A had larger means on Neuroticism, and if Neuroticism has been shown to be negatively related to adjustment, one would expect that Country A would have lower adjustment. If these propositions are true, then they would provide an alternative account for country differences in adjustment heretofore offered.

The incorporation of traits in cross-country and ethnic studies is also interesting for another reason. Dispositional traits are a part of personality that may be relatively (but not absolutely) impervious to cultural and environmental influences. Several lines of evidence support this contention, including studies of the hereditability of personality, parental influence, cross-country stability in personality structure, the temporal stability of adult personality, and comparative studies (McCrae et al., 2000; Yamagata et al., 2006). Traits do change as a function of the environment (Heady \& Wearing, 1989; Roberts \& DelVecchio, 2000; Roberts, Walton, \& Viechtbauer, 
2006; Scollon \& Diener, 2006), but there is some consensus that at least a portion of dispositional traits is hereditary, temperamental, and thus relatively noncultural. If true, and if traits account for country and ethnic differences in adjustment, this would raise the interesting question as to whether previous cross-national or crossethnic differences in adjustment are rooted at least partially in genes. ${ }^{1}$

\section{Overview of the Studies}

We address this possibility in two studies comparing country (Study 1) and ethnic (Study 2) differences on adjustment, incorporating dispositional traits as a potential source of such differences. In Study 1, Americans and Japanese completed measures of adjustment, which were carefully chosen to be the same measures that previous studies have used and for which the observed differences were interpreted as occurring because of something other than traits. We also administered the NEO-FFI, a measure of traits (McCrae \& Costa, in press). We hypothesized that Americans would have higher adjustment scores, replicating previous findings (Chang \& Asakawa, 2003; Chang et al., 2001; Diener, Diener, et al., 1995; Heine \& Lehman, 1995; Heine et al., 1999; Iwata \& Buka, 2002; Kitayama et al., 2000; Oishi et al., 1999). We then used a mediational approach (Baron \& Kenny, 1986) to test whether traits could account for the observed country differences. This procedure is also known as unpackaging in the cross-cultural literature (Bond, 1998; Matsumoto \& Yoo, 2006; Singelis, Bond, Sharkey, \& Lai, 1999), because it unpacks the contents of "culture" by identifying variables that account for observed between-group differences. We hypothesized that there would be significant AmericanJapanese country differences on the five traits, replicating previous findings (Matsumoto, 2006a; McCrae, Costa, del Pilar, Rolland, \& Parker, 1998) and that traits would be related to adjustment in a similar fashion within both countries, both of which are necessary con-

1. Over the years a number of authors have argued that personality is inextricably bound with culture (Markus \& Kitayama, 1998; Schwartz, 1978). We offer no data to resolve this question; instead we investigate the possibility that dispositional traits, regardless of their source, may account for country and ethnic differences in adjustment and that, if at least part of dispositional traits are rooted in biology and genes, then the source of country and ethnic differences in adjustment may not be cultural. 
ditions for mediation. We then hypothesized that traits would mediate the American-Japanese country differences on adjustment.

Study 2 then attempted to accomplish the same goal in a European versus Asian American comparison. Participants completed a variety of adjustment measures, all of which were used in previous studies documenting ethnic group differences. They also completed the same measure of traits used in Study 1. We hypothesized that European Americans would score more positively on adjustment, replicating previous results. We further hypothesized that there would be ethnic group differences on personality, that traits would correlate with adjustment similarly in both ethnic groups, and that traits would account for the observed ethnic group differences in mediational analyses.

\section{STUDY 1}

\section{Method}

\section{Participants}

The participants were 200 American ( 149 women, 51 men; mean age $=20.1$ years) and 128 Japanese ( 89 women, 39 men; mean age $=19.7$ years) university undergraduates recruited from psychology courses at San Francisco State University, USA, and Nihon University and Musashino University, Japan. ${ }^{2}$ All participants were born and raised in their countries and reported English and Japanese as their primary languages. There was no significant difference in age, $F(1,320)=1.16, n s$, or gender distribution, $\chi^{2}(1)=.33, n s$. The American participants self-reported their ethnicities as follows: Caucasian $(n=84)$, Hispanic/Latino $(n=26)$, African American $(n=18)$, Middle Eastern $(n=3)$, Indian $(n=3)$, and bi- or multiethnicity $(n=65)$; one participant's ethnicity was not classified.

\section{Adjustment Measures}

Self-esteem. We used the Collective Self Esteem Scale (CSES; Luhtanen \& Crocker, 1992) and the Rosenberg Self-Esteem scale (RSE; Rosenberg,

2. Actually there were 279 Americans in the original sample. All participants of Asian descent were eliminated from this study because of the possibility of Asian versus non-Asian differences in personality traits and adjustment reported in the literature and in Study 2. Even with the Asian American participants included, the findings reported below were exactly the same. 
1965). The Collective Self-Esteem Scale is a 16 item-questionnaire with a 7-point Likert scale that assesses collective self-esteem in four domains: Membership Self-Esteem, Private Collective Self-Esteem, Public Collective Self-Esteem, and Importance to Identity. After reverse scoring negatively keyed items, items for each domain were averaged; a mean score across all domains was also computed for a total score. Cronbach's $\alpha$ s were acceptable in the United States $(.64, .73, .78, .80$, and .87) and Japan $(.68, .78, .73$, .75 , and .85) for Membership, Private, Public, Identity, and Total, respectively. The findings for the four domain scores were exactly the same as the Total score; thus we report findings using the Total score for parsimony (interested readers can obtain tables of these reports from the first author).

The Rosenberg Self-Esteem Scale assesses global self-esteem related to overall feelings of self-worth or self-acceptance. It consists of 10 items rated on a 4-point Likert scale. A total score was derived from summing all the responses after reverse scoring negatively keyed items. Cronbach's $\alpha$ was acceptable in both the United States (.86) and Japan (.90). A published Japanese version was used in Japan (Yamamoto, Matsui, \& Yamanari, 1982).

Depression. We used the Zung Self-Rating Depression Scale (ZSDS; Zung, 1965), and the Beck Depression Inventory-II (BDI; Beck, Steer, \& Brown, 1996). The Zung scale consists of 20 statements related to symptoms of depression. Each item was self-rated on a 4-point scale ranging from 1 (a little of the time) to 4 (most of the time). After reverse scoring negatively worded items, a total score was computed by summing the items. Cronbach's $\alpha$ was acceptable in both the United States (.76) and Japan (.78). The Beck Depression Inventory is a 21-item self-report instrument, each with four answers differing in severity. The Japanese version was used in Japan (Fukuda \& Kobayashi, 1973). Responses to all items were summed; Cronbach's $\alpha$ was acceptable for both the United States (.88) and Japan (.91).

Well-being. Subjective well-being was assessed either by a list of emotion words used in Kitayama et al.'s (2000) study or by the Satisfaction With Life Scale (SWLS; Diener, Emmons, Larsen, \& Griffin, 1985) and the Daily Satisfaction Assessment form (Oishi, 2002). Kitayama et al. (2000) developed a list of 31 emotion terms in Japanese and English that assessed seven categories of emotions, four of which were used here: positive and interpersonally disengaged, negative and interpersonally disengaged, positive and interpersonally engaged, and negative and interpersonally engaged. The frequency of experience of each emotion term was rated on a 6 -point scale $(1=$ never to $6=$ always $)$, and mean frequency ratings 
for each emotion category were computed. Cronbach's $\alpha$ s were acceptable for both the United States $(.73, .75, .69$, and .72) and Japan (.63, .63, .77, and .81), for positive and negative interpersonally disengaged, and positively and negatively interpersonally engaged, respectively.

The other scale used to measure well-being was a combined SWLS (Diener et al., 1985) and Daily Satisfaction Assessment form (Oishi, 2002). The Satisfaction with Life Scale is a five-item questionnaire with a 7-point Likert scale. Each item was summed for a total score, and Cronbach's $\alpha$ s were acceptable in both the United States (.77) and Japan (.83). The Japanese version was used in Japan (Kamizawa \& Nishimoto, 2003). The Daily Satisfaction Assessment form assesses the degree of daily life satisfaction and consists of three questions, "How was today?" "How satisfied are you with your life today?" and "How was this week?" Respondents answered using a 7 -point scale $(1=$ terrible, $3=$ bad, $4=$ neutral, $5=$ good, $7=$ excellent $)$ or $(1=$ very dissatisfied to $7=$ very satisfied $)$. A total score was derived for a global daily satisfaction score. Cronbach's $\alpha$ s were acceptable for both the United States (.73) and Japan (.70).

Optimism/pessimism bias. We used two optimism/pessimism bias questionnaires: (1) the Future Life Events scale (Weinstein, 1980, 1982, 1987) modified by Heine and Lehman (1995), and (2) the Life Events Questionnaire (LEQ; Schrauger, Mariano, \& Walter, 1998), modified by Chang et al. (2001). The Future Life Events scale included 15 future events (10 negative and 5 positive). Heine and Lehman measured optimistic/pessimistic bias on these 15 future events by using a within-groups measure and a between-groups measure. For the within-groups measure, respondents were asked what they thought the chances were the future events would happen to them, compared to their peers who are of the same sex and students at the same university. The responses were made with a 7 -point scale $(1=$ much below average, $4=$ average, $7=$ much above average), which were recoded into -3 to 3 for the negative events and 3 to -3 for the positive events. Mean scores using these recoded scores were computed for negative and positive events separately. Accordingly, negative scores indicated optimism, whereas positive scores indicated pessimism.

For the between-groups measure, respondents estimated the absolute percentage chance that the event would happen to them and that the event would happen to their same sex peers at the same university. The difference between these was computed for each event. For negative events, the estimated absolute chance to peers was subtracted from the estimated chance to respondent him/herself, and vice versa for positive events. Then, these differences were averaged within negative and positive events separately. Accordingly, negative scores suggested greater 
optimistic tendency, and the positive scores indicated greater pessimistic tendency. ${ }^{3}$

For the negative events, Cronbach's $\alpha$ s were acceptable for all measures for both the United States $(.81, .85)$ and Japan $(.84, .75)$ for the withingroups and between-groups measures, respectively. For the positive events, however, the Cronbach's $\alpha$ s were lower $(.64, .63$ for the United States and $.48, .75$ for Japan). These were likely due to the smaller number of items for positive events and should be taken into account when interpreting the results.

The other scale used to assess optimism or pessimism bias was the Life Events Questionnaire, which includes 48 negative or positive life events that are common to college students. We utilized the same 30 items used by Chang et al. (2001), who found that these 30 events were appraised equivalently by American and Japanese students. Respondents indicated whether, in comparing yourself to others like you, an event was more likely to happen to others than to me (1), equally likely to happen to me and others (2), or more likely to happen to me than to others (3) over the next 2 months. These ratings $(1,2$, and 3$)$ were recoded into $-1,0$, and 1 on the negative events and 1,0 , and -1 on the positive events, and a mean score was computed separately for negative and positive events. Therefore, negative scores indicated an optimistic bias, whereas positive scores indicated a pessimistic bias. Low Cronbach's $\alpha$ s were obtained in the United States (.51 and .66) and Japan (.67 and .62), for negative and positive events, respectively.

Dispositional traits. Traits were assessed by the NEO Five-Factor Inventory (NEO-FFI; Costa \& McCrae, 1992), a 60-item test assessing Neuroticism, Extraversion, Openness, Agreeableness, and Conscientiousness. Participants respond to each item using a 5-point scale $(0=$ strongly disagree to $4=$ strongly agree). There is ample evidence for the crosscultural equivalence in the factor structure and within-country validity of the NEO-FFI, including in Japan (Shimonaka, Nakazato, Gondo, \& Takayama, 1999). After reverse scoring negatively keyed items, items are summed to compute a score for each trait. Cronbach's $\alpha$ s were acceptable for most scores in both the United States $(.82, .76, .76, .69$, and .84) and Japan $(.84, .77, .66, .76$, and .79) for Neuroticism, Extraversion, Openness, Agreeableness, and Conscientiousness, respectively.

3. Heine and Lehman (1995) also investigated the controllability of the event and the availability of stereotypes. In actuality we also included these measures in this study. The findings were consistent with the other measures of optimism/ pessimism; thus we drop these data and findings from this report for parsimony. Interested readers can obtain tables of these findings from the first author. 
Demographics. The participants also completed a brief demographic questionnaire about their age, gender, ethnicity, marital status, economic status of household, place of birth and where they were raised primarily (country and city), years of living in the United States or Japan, religious or spiritual belief, and working hours.

Translations of questionnaires. When published Japanese-translated questionnaires were not available, the original questionnaires in English were translated into Japanese using the back translation technique independently by two Japanese native speakers who were fluent in English. Two additional bilingual Japanese and English speakers (one English native speaker and one Japanese native speaker) consulted and ensured the final translations. The following questionnaires were translated into Japanese in this study: the Collective Self-Esteem Scale, the modified Future Life Events, the Short Daily Satisfaction form (Oishi, 2002), and the modified Life Events Questionnaire.

\section{Procedure}

Participants in both countries participated voluntarily or in fulfillment of course requirements. Participants from San Francisco State University and Musashino University completed the questionnaires at home at their convenience and returned them within a week of distribution. Participants from Nihon University completed the questionnaires in class. All participants completed two sets of questionnaires at two different times. One set consisted of the demographic questionnaire, the NEO-FFI, and two other questionnaires not relevant to this study. The other set of questionnaires included one of each of the scales assessing the dependent variables. One packet included the Collective Self-Esteem Scale, Zung's Self-Rating Depression Scale, the list of emotional terms from Kitayama et al. (2000), and the modified Future Life Events. The other packet included the Rosenberg Self-Esteem Scale, the Beck Depression Inventory, Satisfaction with Life Scale, the Short Daily Satisfaction form, and the modified Life Events Questionnaire. The order of the questionnaires in each packet was randomized, and the order in which the participants completed the two sets of instruments was counterbalanced.

\section{Cross-Country Equivalence in the Measures}

It is important in cross-cultural studies to demonstrate cross-cultural measure invariance, which is typically accomplished through demonstrations of structural equivalence. A baseline model of invariance is typically configural invariance, which exists when items load on the same 
constructs in all groups; this can be tested using separate exploratory factor analyses (EFA) on the items in question in each of the groups. Another level of invariance, metric invariance, exists when items load on the same constructs in all groups to the same degree; this is typically tested using multigroup confirmatory factor analyses (CFA). Another type of invariance refers to the equivalence in the functional relationships among scales, which can be assessed by intercorrelation matrices or structural equation modeling (SEM).

In this study we opted not to conduct CFA because its results are typically misinterpreted to support one structural solution over all others and because replicating a structure through successive unconstrained exploratory procedures may be stronger evidence of structure than an unreplicated constrained confirmatory procedure. Poor fit in CFA can occur because of reasons not related to the cross-cultural structural equivalence in a measure, especially when analyzing item-level data, including differences in properties of distributions (normality, kurtosis, skew). Thus we computed EFAs on each established scale not adapted by us or the previous researchers who used them (CSES, RSE, BDI, Zung, SWLS, NEOFFI) separately for the United States and Japan. ${ }^{4}$ In each case the factor structure was the same.

To establish the functional equivalence of the measures used in the study, we computed a series of intercorrelation matrices among them, separately for the United States and Japan. The first involved the Rosenberg Self-Esteem Scale, the Beck Depression Inventory, the Satisfaction with Life Scale, the Short Daily Satisfaction form, and the modified Life Events Questionnaire. The second involved all scales of the Collective Self-Esteem Scale and the Zung Self-Rating Depression Scale. The third involved the eight scales of the Future Life Events scale. The fourth involved the five scales of the NEO-FFI. In all of these analyses, the same patterns of correlations occurred in both countries, and there was no case in which a correlation was significant but in opposite directions in the two countries. The intercorrelation matrix of the four scales from the Kitayama et al. (2000) rating of emotional terms indicated that five of the six pairs of correlations computed were significant and in the same direction in both countries. Separate multigroup SEMs for each of these sets of measures provided additional support that there were no differences in the relationships among these variables between the United

4. Because the other scales were modified by us and the previous researchers and because there are no previous data concerning the factor structure of them, there is no basis to determine the validity of the factor structures in an exploratory or confirmatory fashion. And in any case our goal was to specifically use the same measures used in previous research. 


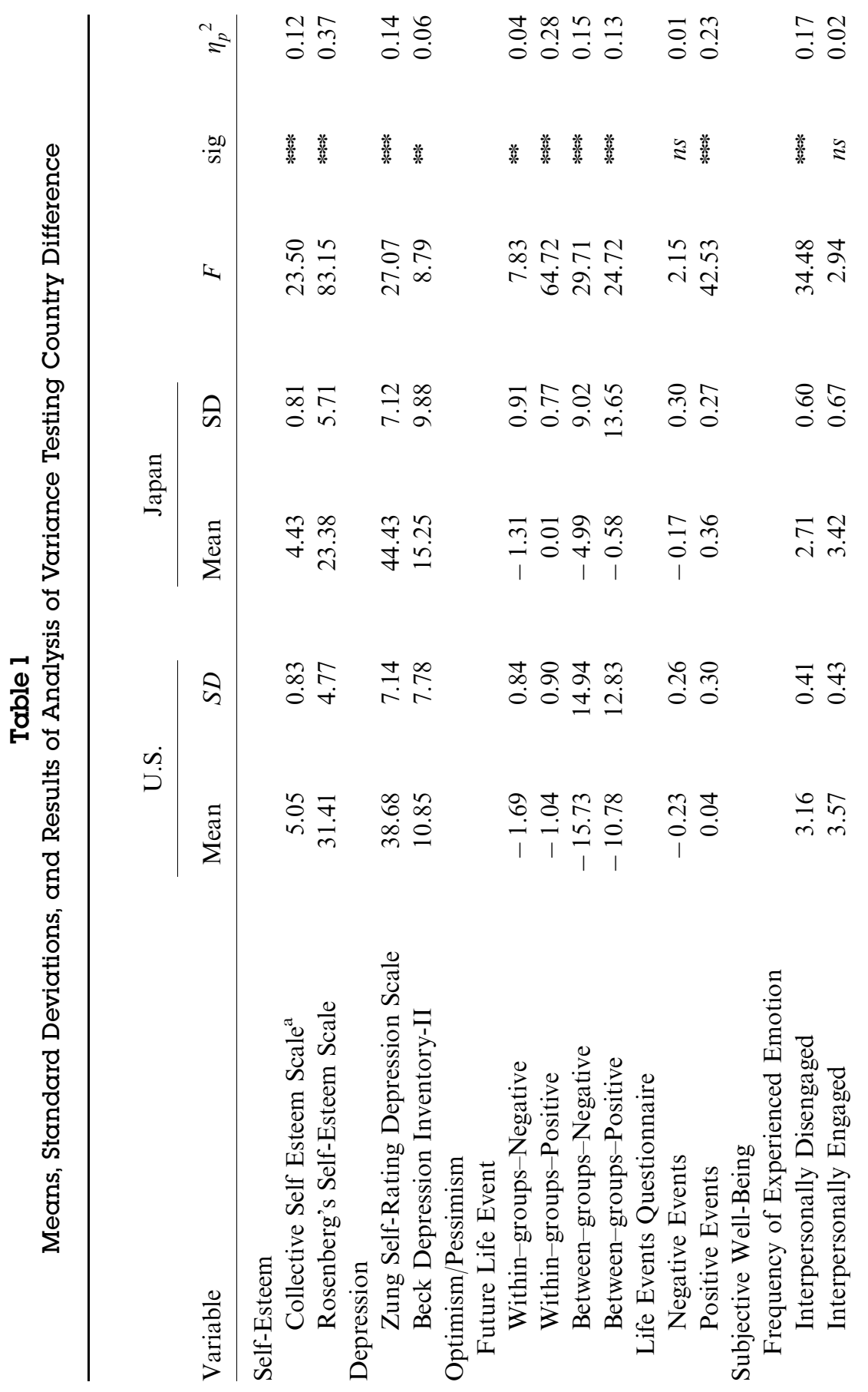




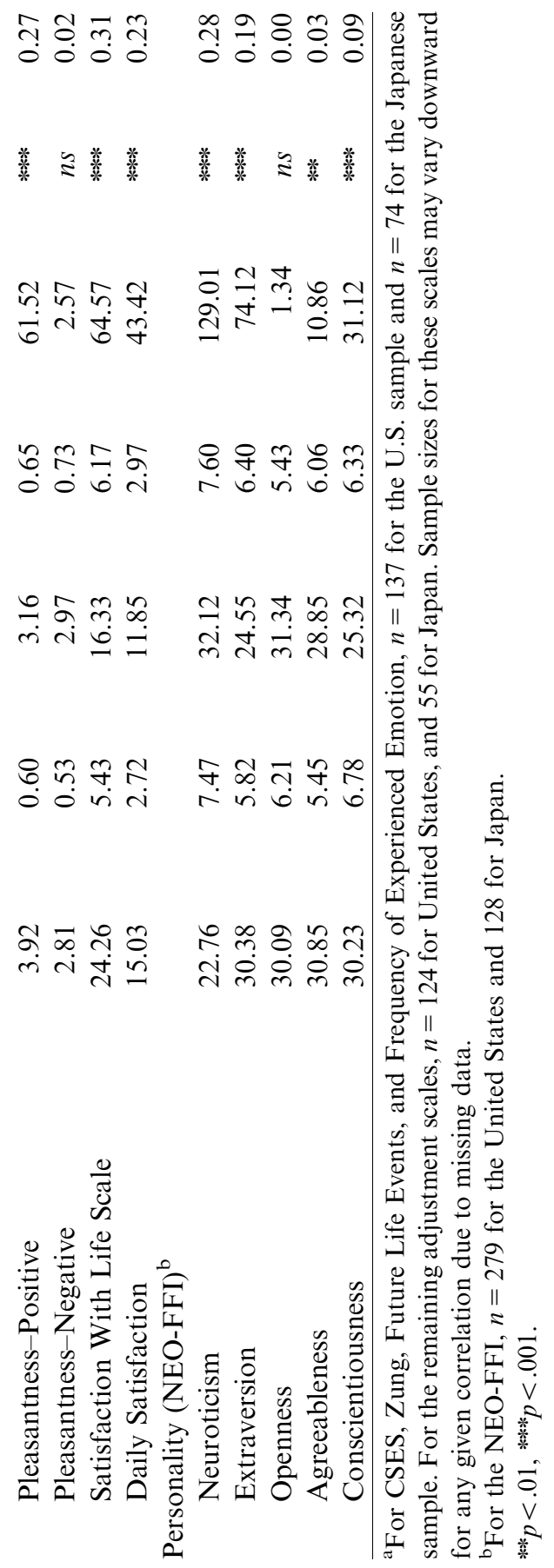


States and Japan (findings available from the first author). In addition to the similarities in the internal reliabilities reported earlier, these findings provided strong support for the cross-cultural structural equivalence of the measures used in this study.

\section{Results}

\section{Country Differences}

We computed one-way analyses of variance (ANOVA) on each variable using country as a factor (Table 1). As predicted, the Japanese had significantly lower scores on the Collective Self-Esteem Scale, the Rosenberg Self-Esteem Scale, the Satisfaction with Life Scale, and Daily Satisfaction; had higher scores on both depression scales; exhibited more pessimistic bias on five of the six scales measuring this bias; and reported less positive experiences. These findings replicated those of previous studies using these measures comparing Americans and Japanese. Moreover, a number of these differences were associated with large effect sizes. The Japanese also had significantly higher scores on Neuroticism, whereas the Americans had significantly higher scores on Extraversion, Agreeableness, and Conscientiousness. These findings replicate previous findings comparing these traits between these two countries (Matsumoto, 2006a; McCrae, 2002).

\section{Within-Country Relationships Between Traits and Adjustment}

We computed correlations between the five traits and all adjustment variables, separately for the United States and Japan (Table 2). As expected, Neuroticism and Extraversion were correlated with adjustment, but Agreeableness and Conscientiousness were also correlated with many of the adjustment variables. These findings replicate those reported earlier and extend them to a different country. Of particular note was the fact that in no case was the correlation between a trait and an adjustment variable significant but in opposite directions in the two countries. There were several instances in which a correlation was significant for one country but not the other (e.g., Agreeableness and Conscientiousness with Satisfaction with Life Scale and Daily Satisfaction). These may indicate culturespecific functioning for specific traits with specific types of adjustment and should be followed in the future. 


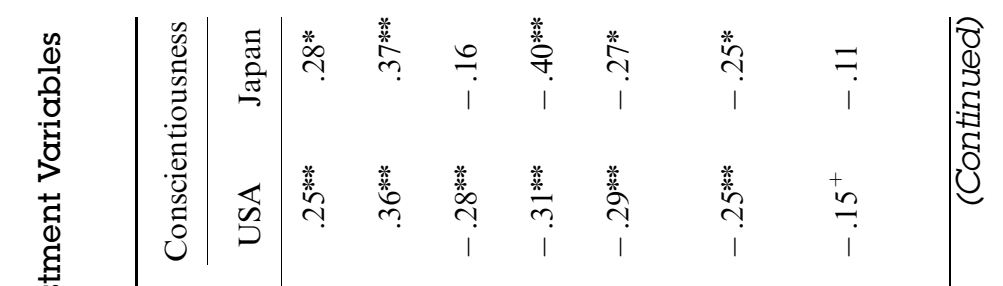

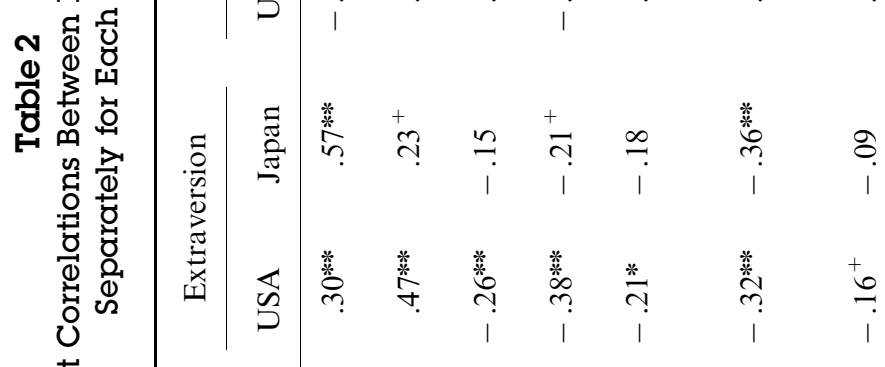

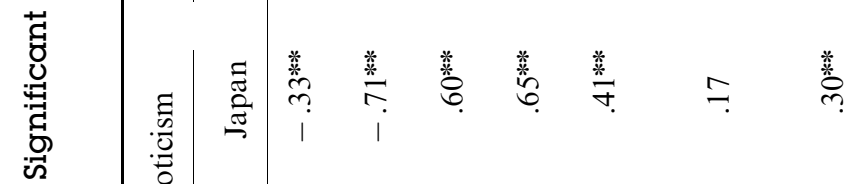

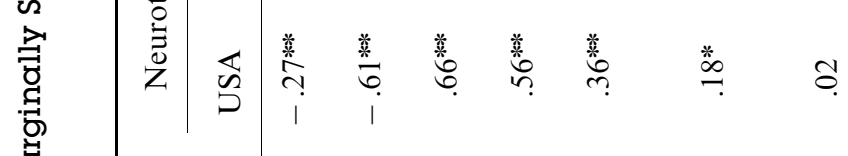

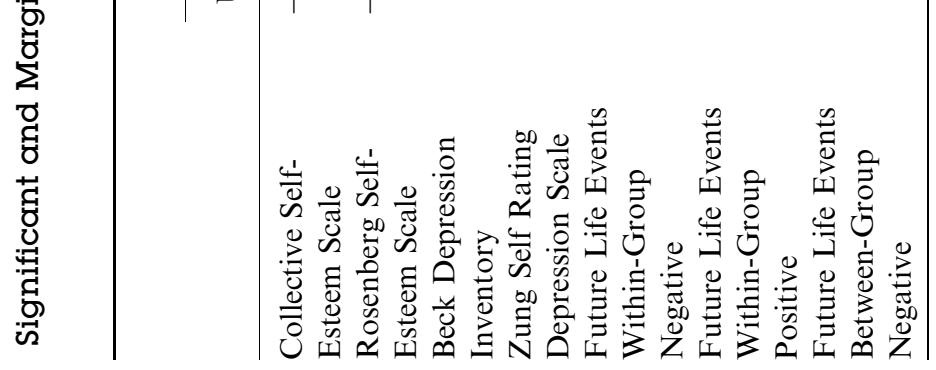




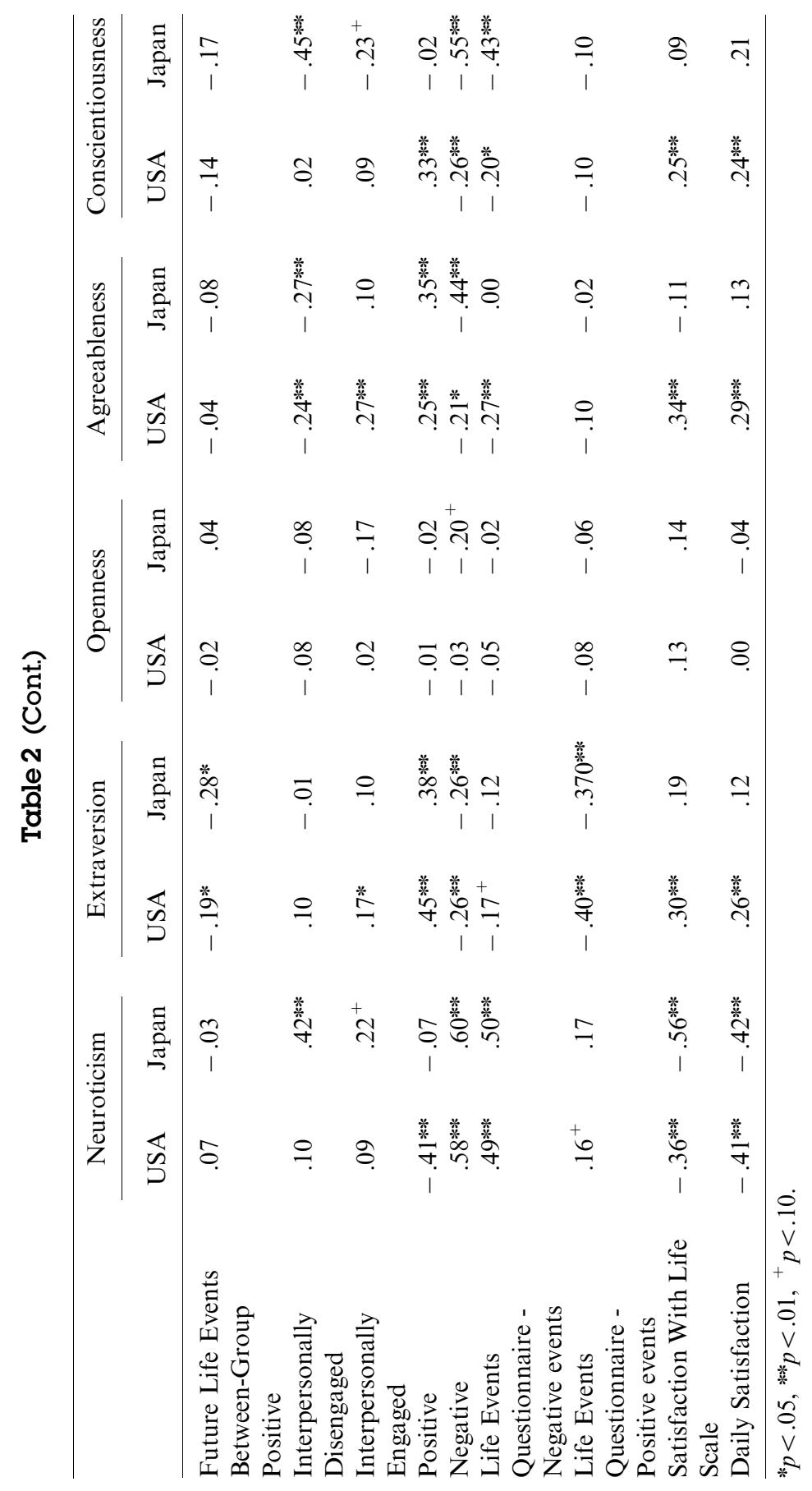




\section{Do Dispositional Traits Mediate the Observed Country Differences?}

The logic of testing mediation (Baron \& Kenny, 1986) applied to the variables in this study would suggest that country has an effect on the adjustment variables, country has an effect on the mediating personality variables, and personality is associated with the adjustment variables, all of which were documented in the findings reported above. Over the years at least 14 significance tests of mediation have been developed; MacKinnon, Lockwood, Hoffman, West, and Sheets (2002) report a Monte Carlo study in which they demonstrated differences among them in terms of Type I error rates and statistical power. In this study we utilized the Freedman and Schatzkin (1992) difference in coefficients test, which requires hierarchical regressions to be computed and tests the difference in the coefficients associated with the country effect on the adjustment variables before and after the mediating personality variables are accounted for. MacKinnon and colleagues (2002) report that this test was one of two that had the greatest power and most accurate Type I error rates.

We performed a series of hierarchical multiple regressions, one for each dependent measure that produced a significant country difference reported in Table 1, in which country was entered in Step 1 and the five traits in Step 2. (The significant country effects on the five traits justified these inclusions.) The regression coefficients for country between Steps 1 and 2 were tested. To aid in the interpretation of the findings, we also computed semipartial correlations associated with the country effect at each step.

The findings were quite clear (Table 3). Of the 13 adjustment variables tested, 12 were associated with statistically significant differences in the regression coefficients for country from Step 1 to Step 2. Three were not significant on the second step, indicating complete mediation. Inspection of the semipartial correlations for country from Step 1 to Step 2 indicated that, even for those variables that were partially mediated, traits accounted for the vast majority of the country effects (mean percentage of the original country effects accounted for $=86 \%$ ). For all intents and purposes, therefore, the American-Japanese country differences on the dependent measures were nearly completed mediated by individual differences in traits.

We also recomputed the mediation analyses, using each the traits separately. Inclusion of Neuroticism on the second step of the regressions resulted in 10 (of 13) significant mediations; Extraversion 


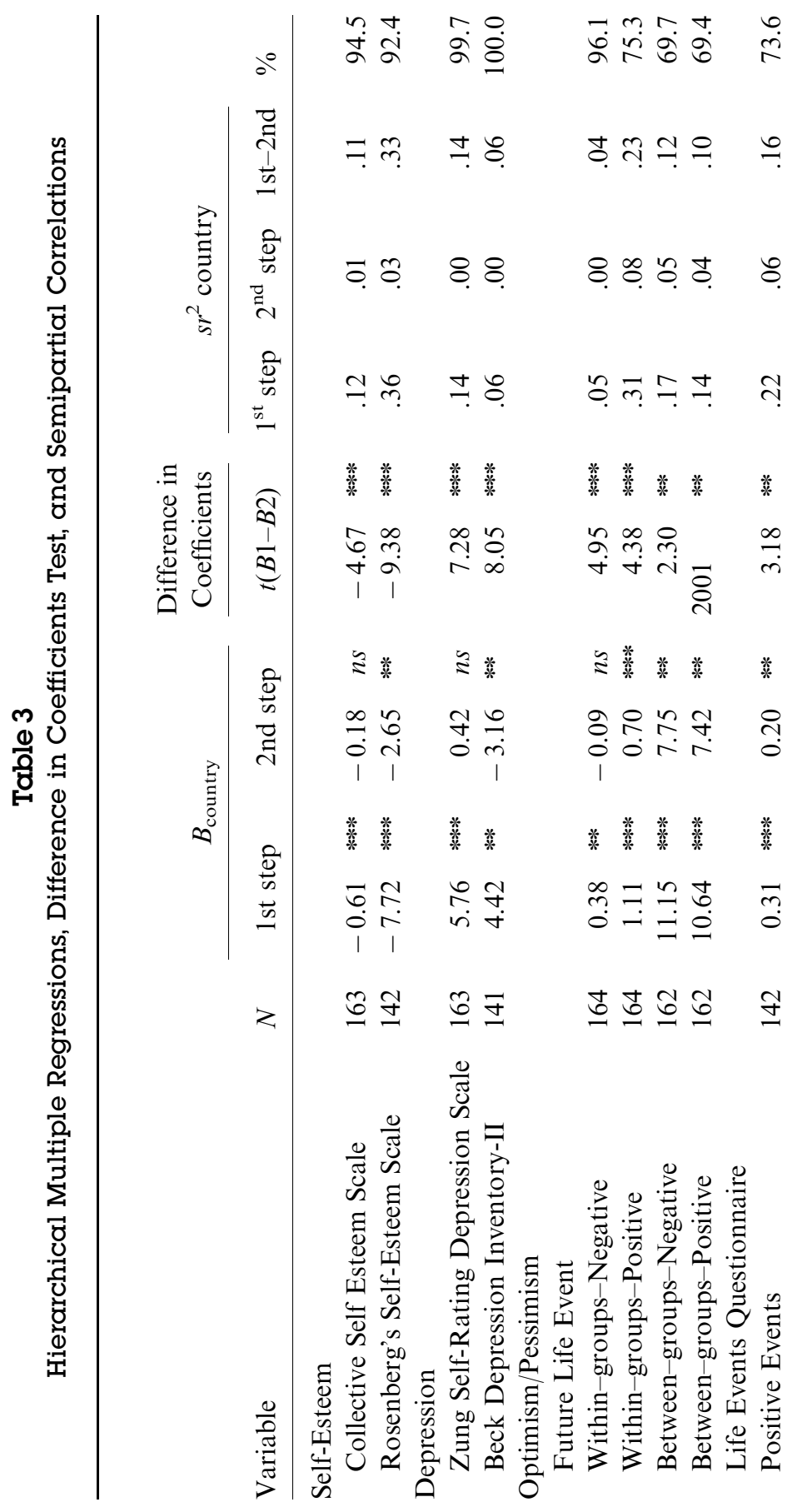




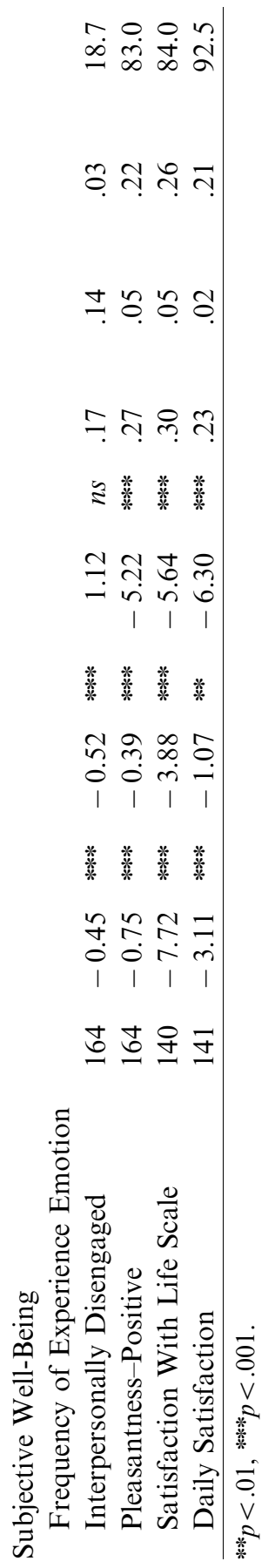


produced 11, Agreeableness produced 10, and Conscientiousness produced 10 . Interestingly, Openness only produced two significant mediations. When Neuroticism and Extraversion were used as mediators, they alone accounted for the vast majority of the variances attributable to country (13 of 13 significant mediations). (Tables of these analyses available from the first author.)

\section{Reversing the Regression Analyses}

One argument against the logic of the above findings would suggest that the dependent measures were proxy measures of traits and thus of course they would mediate country differences on them. If this were true, reversing the analyses should produce the same effect; that is, adjustment should mediate the country differences on the traits. To test this idea, we therefore performed hierarchical regressions on each of the traits, entering country on the first step and then the dependent variables on the second. Across the 13 (dependents) $\times 5$ (traits) analyses, the dependents did indeed mediate the country differences in almost all analyses. However, the country regression coefficient was still significant in nearly all analyses (96\%), and the semipartial correlation differences from Step 1 to Step 2 indicated that in general the country differences were still sizable (mean percentage of the original country effects accounted for $=47 \%$; tables of these analyses are available from the first author). We concluded, therefore, that the adjustment variables were not merely proxy measures of traits.

\section{Discussion}

Dispositional traits accounted for the observed American-Japanese country differences in a variety of measures of adjustment. These findings were not produced by scalar inequivalence between the countries, as the measures were associated with acceptable internal reliabilities, similar structural relationships, and similar predictive validities with the traits. The findings could not be attributed to specific scales, as two scales assessing the same construct were used, nor could the findings be attributed to halo effects from common administration because the administrations of the mediators and the dependent variables were separated by at least 2 weeks. These findings provide an alternative account of country differences in adjustment and suggest that those differences may be explained by differences in 
aggregate levels of traits. That is, countries may differ in their mean levels of adjustment not only because of cultural factors but also because of differences in the distribution of traits in their populations.

These findings raise the possibility that ethnic group differences in adjustment may be accounted for by traits. Previous studies have demonstrated that European Americans tend to score more positively on adjustment (e.g., less anxiety or depression), whereas Asian Americans tend to score more negatively (Lee, Okazaki, \& Yoo, 2006; Norasakkunkit \& Kalick, 2002; Okazaki, Liu, \& Longworth, 2002). Moreover, as with the cross-country literature, ethnic group differences on adjustment have been typically interpreted as arising because of sources other than traits. For instance, differences between European and Asian Americans on measures of depression and social anxiety have been interpreted to result from differences in culturally based self-construals (Norasakkunkit \& Kalick, 2002), cultural orientation and interpersonal relationships (Wong, 2001), and cultural norms about mental health problems (Okazaki \& Kallivayalil, 2002). The findings from Study 1, however, raise the possibility that traits account for these ethnic group differences.

\section{STUDY 2}

\section{Method}

\section{Participants}

The participants were 110 European Americans ( 82 women, 28 men, mean age $=20.33$ years) and 81 Asian Americans (59 women, 22 men, mean age $=19.67$ years). All were university undergraduates recruited at San Francisco State University participating in partial fulfillment of class requirements. ${ }^{5}$ All were born and raised in the United States, reported English as their primary language, and self-reported their ethnicities.

\section{Dependent Measures}

Anxiety. Anxiety was measured by two scales, one of which was the Fear of Negative Evaluation scale (FNE; Watson \& Friend, 1969), a 30-item instrument designed to measure aspects of social anxiety, the fear of receiving negative evaluations from others, and a fear of the loss of social

5. The Asian American sample included 31 individuals of Chinese, 3 of Japanese, 2 of Korean, 4 of Vietnamese, 2 of Cambodian, 1 of Laotian, 24 of Pilipino, and 4 of Pacific Islander descent. The remainder was unspecified. 
approval. Items on the measure include signs of anxiety and ineffective social behaviors that would incur disapproval by others. Participants respond using a true/false format, and items are summed to create scores. Cronbach as were acceptable for both European (.89) and Asian Americans (.91).

The other scale was the Social Avoidance and Distress Scale (SAD; Watson \& Friend, 1969), a 28-item measure developed to assess anxiety in social situations. The SAD assesses two aspects of anxiety and the deliberate avoidance of social situations. Participants respond using a true/false format, and items are summed to create scores. Cronbach $\alpha$ s were acceptable for both European (.89) and Asian Americans (.91).

Depression. Two scales were used to measure depression. One was the Center for Epidemiological Studies-Depressed Mood Scale (CES-D; Radloff, 1977), a 20-item questionnaire designed to measure depression in the general population. Questions are rated on a 4-point scale $(1=$ rarely or none of the time and $4=$ most or all of the time $)$. Cronbach as were acceptable for both European (.87) and Asian Americans (.90). The other scale was the Beck Depression Inventory-II. Cronbach $\alpha$ s were acceptable for both European (.88) and Asian Americans (.89).

Optimism versus pessimism. Optimism versus pessimism was measured using two scales. One was the Future Outlook Scale (FOS; Oishi, Wyer, \& Colcombe, 2000), a 20-item measure. Participants rated the likelihood that each of 10 positive and 10 negative events would happen to them in the near future on a scale ranging from 1 (extremely unlikely or almost $0 \%$ ) to 7 (extremely likely or almost 100\%). Both the negative and positive life events are relatively common in a college environment. Cronbach as were acceptable for both European $(.84, .79)$ and Asian Americans $(.68, .75)$ for positive and negative events, respectively.

The other scale was the Extended Life Orientation Test (ELOT; Chang, Maydeau-Olivares, D'Zurilla, 1997), a 15-item measure of optimism and pessimism where brief statements are rated on a 5-point Likert scale. Two subscales are scored (optimism and pessimism). Cronbach $\alpha$ s were acceptable for both European (.72 and .84) and Asian Americans (.86 and .88$)$, respectively.

Well-being. Well-being was measured using two scales. One was the Personality Structure of Affect (PSA; Diener, Smith, \& Fujita, 1995), which measures the emotional lives of participants using 24 emotion terms that can be grouped to form scales for six emotion categories: fear, anger, sadness, shame-guilt, joy, and love. Participants rate how frequently they felt the emotion during the past month when they were awake, using a 7-point scale ranging from never (1) to always (7). Cron- 
bach $\alpha$ s were acceptable for both European $(.84, .85, .88, .88, .81, .85)$ and Asian Americans $(.83, .85, .90, .86, .77, .88)$, for each emotion, respectively. The other scale was the combined Satisfaction with Life Scale (Diener et al., 1985) and the Daily Satisfaction Assessment Form (Oishi, 2002) used in Study 1. Cronbach $\alpha$ s were acceptable for both European (.69) and Asian Americans (.87).

Personality and Demographics. The NEO-FFI was used. Cronbach's $\alpha$ s were acceptable for European $(.84, .78, .75, .72, .85)$ and Asian Americans $(.80, .78, .58, .62, .80)$ for Neuroticism, Extraversion, Openness, Agreeableness, and Conscientiousness, respectively. Participants were also asked for general demographic information that included age, gender, ethnicity, religion, socioeconomic status, place of birth, and place primarily raised.

\section{Procedures}

All participants completed two sets of questionnaires at two times separated by at least 2 weeks. One set consisted of the demographic questionnaire, the NEO-FFI, and two other questionnaires not relevant to this study. The other set of questionnaires included one of each of the scales assessing the dependent variables. One packet included the Fear of Negative Evaluation Scale, the Center for Epidemiological StudiesDepression scale, the Future Outlook Scale, and the Personality Structure of Affect. The other packet included the Social Avoidance and Distress Scale, the Beck Depression Inventory, the Extended Life Orientation Test, and the combined Satisfaction with Life Scale and the Daily Satisfaction Assessment form. The order of the questionnaires in each packet was randomized, and the order in which the participants completed the two sets of instruments was counterbalanced.

\section{Cross-Ethnicity Structural Equivalence}

As in Study 1, we examined the structural equivalence among the measures using two sets of intercorrelation matrices, separately for each packet of measures used. The same pattern of correlations occurred in both matrices for both ethnicities, and there was no case in which a correlation was significant but in opposite directions in the two countries. Multigroup SEMs produced the same results. These findings provided strong support for the cross-ethnicity structural equivalence of the measures used in this study. 


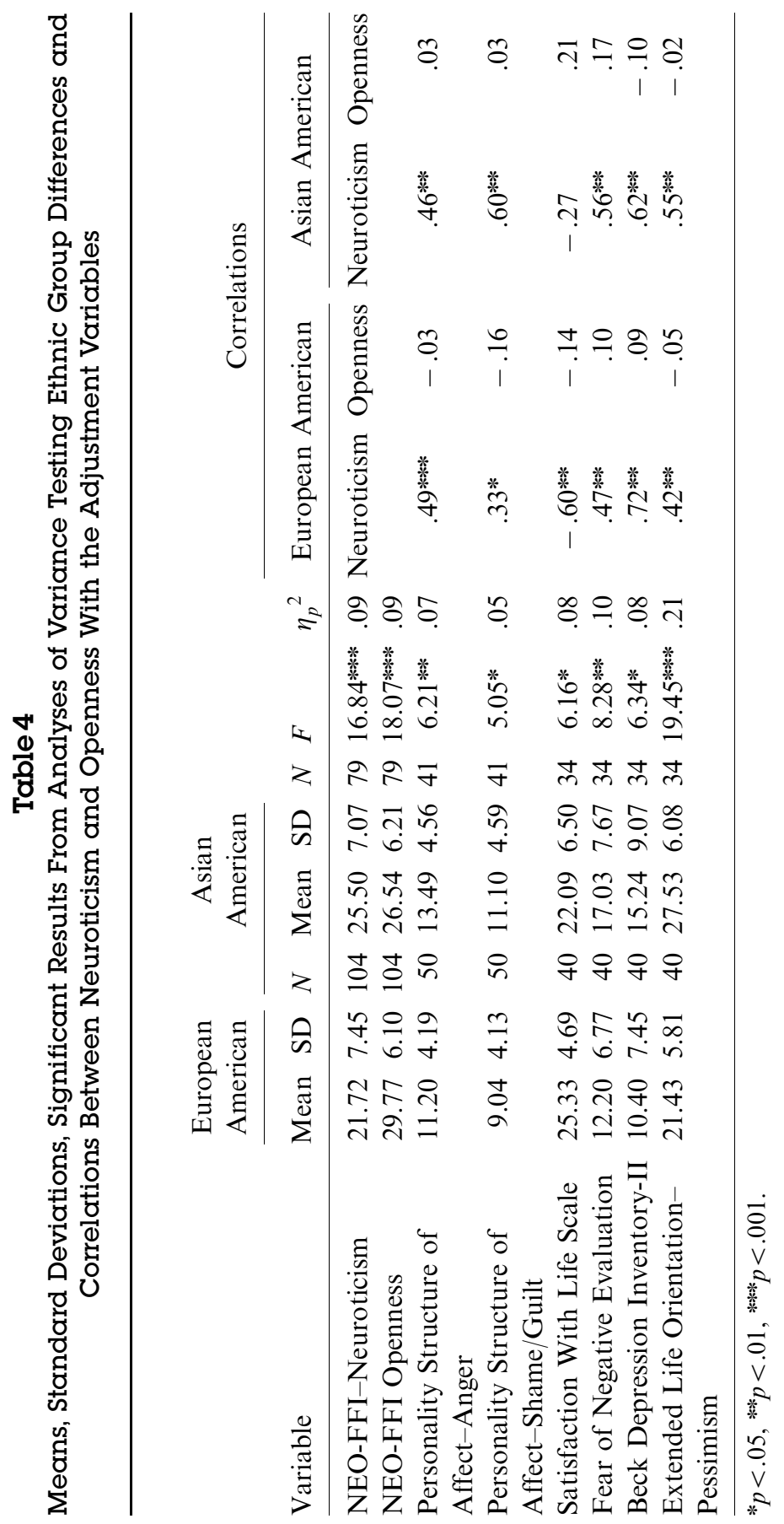




\section{Results}

\section{Ethnic Group Differences}

ANOVAs were computed on each of the dependent measures, using ethnicity as the factor. Significant results are shown in Table 4. As predicted, Asian Americans had significantly higher scores than European Americans on the anger and shame-guilt subscales of the Personality Structure of Affect scale, the Fear of Negative Evaluation scale, the Beck Depression Inventory, and the Pessimism subscale of the Extended Life Orientation scale. European Americans, however, had higher scores on the Satisfaction with Life Scale. These findings supported the hypothesis that Asian Americans would have lower scores on adjustment.

ANOVAs also indicated significant ethnic group differences on traits (Table 4). Asian Americans had significantly higher scores on Neuroticism, whereas European Americans had higher scores on Openness. These ethnic group differences are new in the literature. It is curious that the Asian Americans were lower than European Americans on Openness, as there were no differences between Americans and Japanese in Study 1. We have no post hoc explanation for this difference but note here that most of the Asian Americans in Study 2 were of Chinese and Filipino ancestry (and not Japanese). The nonfinding on Conscientiousness replicates a previous nonfinding (Lee et al., 2006).

\section{Within-Group Relationships Between Traits and Adjustment}

We computed correlations between traits and the adjustment variables that were associated with significant ethnic differences. Neuroticism was significantly correlated with each of the adjustment scales for both European and Asian Americans (Table 4, right). Openness was not correlated with any of the adjustment scales. (Tables of correlations between all adjustment variables and all traits separately for the two ethnic groups are available from the first author.)

\section{Do Traits Mediate the Observed Ethnic Group Differences?}

We performed the same types of hierarchical multiple regressions as in Study 1 on each dependent measure that produced a significant ethnic group difference reported in Table 4. Ethnicity was entered in Step 1, 
and Neuroticism and Openness were entered in Step 2. The regression coefficients for ethnicity between Steps 1 and 2 were tested using the Freedman and Schatzkin (1992) difference in coefficients test (MacKinnon et al., 2002). All mediation $t$ tests were significant. For all dependent measures except one, the regression coefficients for ethnicity were not significant in the second step, indicating complete mediation of the ethnic group differences. The only dependent measure with a surviving significant regression coefficient was the pessimism subscale of the Extended Life Orientation Test, indicating partial mediation. The same results were obtained when only Neuroticism was used.

\section{Discussion}

The overall findings of Study 2 parallel those of Study 1. The ethnic group differences observed replicated previous findings using the same scales (Norasakkunkit \& Kalick, 2002; Okazaki, 1997; Okazaki \& Kallivayalil, 2002), and the mediation analyses indicated that traits accounted for the differences. As in Study 1, the findings could not be attributed to specific scales, as two scales assessing the same construct were used, nor could the findings be attributed to halo effects from common administration, because the administrations of the mediators and the dependent variables were separated by at least 2 weeks. Also, the findings could not be attributed to scalar inequivalence between the ethnic groups.

The ethnic differences observed have several potential sources. One may be rooted in differential experiences for European and Asian Americans. For instance, subtle experiences of oppression such as those that occur in fulfilling expectations of the Model Minority myth may reduce Openness, increase Neuroticism, and reduce adjustment in Asian Americans. Alternatively, immigrant groups may come with differential amounts of different traits (and thus different adjustment levels) in a self-selection process. Future research will need to address these, and other, possible sources of these differences.

\section{GENERAL DISCUSSION}

The findings reported here suggest that a possible source of country and ethnic group differences on variables assessing mental health and adjustment is dispositional traits. In our studies, the United States had higher mean levels of Extraversion, Agreeableness, and 
Conscientiousness, whereas Japanese had higher means on Neuroticism, and the U.S.-Japan differences on adjustment could be almost entirely accounted for by the mean differences on traits. That is, the United States may have had higher adjustment scores because they have more extroverts and fewer neurotics than Japan and because these traits are related to adjustment. Likewise, European Americans may have scored higher on positive adjustment scales than Asian Americans because of their lower scores on Neuroticism.

The findings were not produced without limitations. Perhaps largest among these was the use of a concurrent design in which traits and adjustment were measured essentially at the same time. Although there is some evidence that the effect of traits on adjustment in crosslagged analyses is larger than the influence of adjustment on traits (Scollon \& Diener, 2006), future studies involving cross-lag designs or experiments are necessary to demonstrate the causal role of traits in influencing adjustment. Another limitation concerned the possible overlap in item content between the adjustment and trait measures. Although this concern was somewhat mitigated by our findings using the reverse regressions, future studies will need to incorporate the use of other methods, especially those rooted in behaviors, to further demonstrate the linkage between traits and adjustment.

Despite these limitations, the current findings offer a new perspective on ways to understand the potential sources of country differences on psychological processes like adjustment. The dominant approach to interpreting country differences is to invoke the concept of culture and its related products such as self (Markus, 1977; Markus, Uchida, Omoregie, Townsend, \& Kitayama, 2006). The findings reported here, however, suggest that traits are also an important variable to consider. Entertaining the possibility that multiple potential sources of variability may account for country and ethnic group differences allows for a more comprehensive yet nuanced view of the influence of culture, personality, and basic human nature on adjustment, and cross-cultural researchers may consider incorporating such sources in their studies.

Which traits? Previous monocultural studies (reviewed earlier) indicated that Extraversion and Neuroticism and, to a lesser extent, Agreeableness, Conscientiousness, and Openness were related to adjustment on the individual level. In our Study 1, Extraversion and Neuroticism were associated with the largest U.S.-Japan country differences and accounted almost entirely for the country 
differences on the adjustment variables. In Study 2, Neuroticism and Openness were associated with ethnic group differences, and Neuroticism accounted for ethnic group differences in adjustment. These findings suggest a strong role for Neuroticism in accounting for group and individual differences in adjustment; the role of other traits may be dependent on the specific groups being compared.

That traits account for country differences in adjustment leads to interesting speculations about the relative influence of biology and environment in producing country differences. If at least some part of dispositional traits is present at birth and genetically based, an idea supported by some evidence (McCrae \& Costa, in press; McCrae et al., 2000; Yamagata et al., 2006), that would suggest that at least part of the country differences in adjustment result from biological differences - more specifically, national differences in the distribution of alleles for personality traits. To our knowledge, however, there are little data to support such contentions, and what data do exist are still speculative (Gelernter et al., 1998). Future studies are needed to examine this possibility.

At the same time, there is a part of traits that is malleable to the environment. The expression of traits, especially in adult life, is highly dependent on the cultural framework within which individuals exist, because individuals can choose from a variety of culturally framed appropriate responses with which to express their underlying dispositions (McCrae \& Costa, 1999). And cultural experiences are associated with changes in mean levels and consistency in traits across the life span (Roberts \& DelVecchio, 2000; Roberts et al., 2006). Thus it may be that the part of traits that is not genetically based is what drives country differences in adjustment. If so, future research needs to turn its efforts to examining the cultural practices that influence these aspects of dispositional traits and link them empirically to adjustment.

Also, there are many nontrait aspects of personality - such as role identities; narratives; motives; individual-level values, attitudes, opinions; experiences; and self-construals - and these are more heavily influenced by culture. These aspects of personality require interaction with the environment and life experiences, both of which form the basis of cultural influences. Some theorists argue, in fact, for the mutual constitution of culture and personality (Markus \& Kitayama, 1998), and many writers recognize the inherent and somewhat inextricable relationship between culture and these aspects of personality. These nontrait aspects of personality may account for 
country differences in adjustment. On the individual level, for instance, having goals and making progress toward them is related to well-being (Emmons, 1986; Emmons \& Diener, 1985); having a coherent sense of one's personality and acting in accordance with that understanding is also related to well-being across cultures (Sheldon et al., 2004; Sheldon, Ryan, Rawsthorne, \& Ilardi, 1997). These findings suggest a role for these nontrait aspects of personality in also accounting for country differences in adjustment and should be examined in future cross-cultural work.

Cumulatively, the findings reported here strongly suggest that researchers incorporate a host of variables heretofore not considered in accounting for country or ethnic group differences. As mentioned above, most contemporary approaches to these differences almost uniquely and ubiquitously invoke the concept of culture to explain the differences. This may reflect a bias in the way we attempt to understand country or ethnic group differences. Country and ethnicity are quasi-experimental variables that denote many potential sources of differences, and researchers interested in such differences can incorporate both cultural (e.g., child-rearing practices, self-construals) and noncultural (e.g., traits) variables in their studies. Analyses can focus on the relative contributions of different potential sources on the variables of interest. It is entirely possible, for instance, that the same sets of explanatory variables have different contributions for different dependent variables, or even the same dependents measured in a different way or in different situational contexts. Cultural differences in adjustment may be more or less apparent in different contexts (Oishi, Diener, Scollon, \& BiswasDiener, 2004), and the relative contributions of culture, nontrait aspects of personality, and traits may differ across contexts. These studies will undoubtedly be more complex, but we believe that this complexity is precisely what the next generation of cultural research should engage in. More complex models of the potential sources of country and ethnic group differences are warranted, along with more nuanced views of the nature and role of culture itself.

\section{REFERENCES}

Allik, J., \& McCrae, R. R. (2002). A Five-Factor Theory perspective. In R. R. McCrae \& J. Allik (Eds.), The Five-Factor Model of personality across cultures (pp. 303-322). New York: Kluwer Academic/Plenum Publishers. 
Allik, J., \& McCrae, R. R. (2004). Towards a geography of personality traits: Patterns of profiles across 36 cultures. Journal of Cross-Cultural Psychology, 35, 13-28.

Baron, R. M., \& Kenny, D. A. (1986). The moderator-mediator variable distinction in social psychological research: Conceptual, strategic, and statistical considerations. Journal of Personality and Social Psychology, 51, 11731182 .

Beck, A. T., Steer, R. A., \& Brown, G. K. (1996). BDI-II: Beck Depression Inventory Manual (2nd ed.). San Antonio, TX: The Psychological Corporation.

Bond, M. H. (1998). Social psychology across cultures: Two ways forward. In J. G. Adair, D. Belanger, \& K. L. Dion (Eds.), Advances in psychological science: Social, personal, and cultural aspects (Vol. 1, pp. 137-150). Hove, UK: Psychology Press, Ltd.

Chang, E. C., \& Asakawa, K. (2003). Cultural variations on optimistic and pessimistic bias for self versus a sibling: Is there evidence for self-enhancement in the West and for self-criticism in the East when the referent group is specified? Journal of Personality and Social Psychology, 84, 569-581.

Chang, E. C., Asakawa, K., \& Sanna, L. J. (2001). Cultural variations in optimistic and pessimistic bias: Do Easterners really expect the worst and Westerners really expect the best when predicting future life events? Journal of Personality and Social Psychology, 81, 476-491.

Chang, E. C., Maydeau-Olivares, A., \& D'Zurilla, T. (1997). Optimism and pessimism as partially independent constructs: Relationship to positive and negative affectivity and psychological well-being. Personality and Individual Differences, 23, 433-440.

Costa, P. T., \& McCrae, R. R. (1980). Influence of extraversion and neuroticism on subjective well-being: Happy and unhappy people. Journal of Personality and Social Psychology, 38, 668-678.

Costa, P. T., \& McCrae, R. R. (1992). Revised Neo-Personality Inventory (NEO$P I-R)$ and Neo Five Factor Inventory (NEO-FFI). Odessa, FL: Psychological Assessment Resources.

DeNeve, K. M., \& Cooper, H. (1998). The happy personality: A meta-analysis of 137 personality traits and subjective well-being. Psychological Bulletin, 124, 197-229.

Diener, E., Diener, M. L., \& Diener, C. (1995). Factors predicting the subjective well being of nations. Journal of Personality and Social Psychology, 69, 851864.

Diener, E., Emmons, R. A., Larsen, R. J., \& Griffin, S. (1985). The satisfaction with life scale. Journal of Personality Assessment, 49, 71-75.

Diener, E., \& Lucas, R. E. (1999). Personality and subjective well-being. In D. Kahneman, E. Diener, \& N. Schwarz (Eds.), Well-being: The foundations of hedonic psychology (pp. 213-229). New York: Russell Sage Foundation.

Diener, E., Oishi, S., \& Lucas, R. E. (2003). Personality, culture, and subjective well-being: Emotional and cognitive evaluations of life. Annual Review of Psychology, 54, 403-425.

Diener, E., Smith, H., \& Fujita, F. (1995). The personality structure of affect. Journal of Personality \& Social Psychology, 69, 130-141. 
Eid, M., \& Diener, E. (2004). Global judgments of subjective well-being: Situational variability and long-term stability. Social Indicators Research, 65, 245277.

Emmons, R. A. (1986). Personal strivings: An approach to personality and subjective well-being. Journal of Personality and Social Psychology, 47, 1105-1117.

Emmons, R. A., \& Diener, E. (1985). Personality correlates of subjective wellbeing. Personality and Social Psychology Bulletin, 11, 89-97.

Freedman, L. S., \& Schatzkin, A. (1992). Sample size for studying intermediate endpoints within intervention trials of observational studies. American Journal of Epidemiology, 136, 1148-1159.

Fujita, F., \& Diener, E. (2005). Life satisfaction set point: Stability and change. Journal of Personality and Social Psychology, 88, 158-164.

Fukuda, K., \& Kobayashi, S. (1973). Jiko-hyouka-shiki yokuuts-sei shakudo no kenkyu [A study on a self-rating depression scale]. Psychiatria et Neurologia Japonica, 75, 673-679.

Gelernter, J., Kranzler, H., Coccaro, E., Siever, L., Siever, L., \& New, A. (1998). Serotonin transporter protein gene polymorphism and personality measures in African American and European American samples. American Journal of Psychiatry, 155, 1332-1338.

Heady, B., \& Wearing, A. (1989). Personality, life events, and subjective wellbeing: Toward a dynamic equilibrium model. Journal of Personality and Social Psychology, 57, 731-739.

Heine, S. J., \& Lehman, D. R. (1995). Cultural variation in unrealistic optimism: Does the West feel more invulnerable than the East? Journal of Personality and Social Psychology, 68, 595-607.

Heine, S. J., Lehman, D. R., Markus, H. R., \& Kitayama, S. (1999). Is there a universal need for positive self-regard? Psychological Review, 106, 766-794.

Heine, S. J., \& Norenzayan, A. (2006). Why cross-cultural research is central to scientific progress in psychology. Perspectives on Psychological Science, 1, 251269.

Inglehart, R. (1998). Modernizacion y postmodernizacion. El cambio cultural, economico y polotico en 43 sociedades. Madrid, Spain: CIS.

Iwata, N., \& Buka, S. (2002). Race/ethnicity and depressive symptoms: A crosscultural/ethnic comparison among university students in East Asia, North and South America. Social Science and Medicine, 55, 2243-2252.

Iwata, N., \& Higuchi, H. R. (2000). Responses of Japanese and American university students to the STAI items that assess the presence or absence of anxiety. Journal of Personality Assessment, 74, 48-62.

Kamizawa, T., \& Nishimoto, N. (2003). Shukan-teki koufukukan ni kansuru kiso kenkyu: SWLS wo moshite [A fundamental study on subjective well-being utilizing the SWLS]. Kansai Fukushi Kagaku Daigaku Kiyou, 6, 163-170.

Kitayama, S., Markus, H. R., \& Kurokawa, M. (2000). Culture, emotion, and well-being: Good feelings in Japan and the United States. Cognition and Emotion, 14, 93-124.

Kitayama, S., Mesquita, B., \& Karasawa, M. (2006). Cultural affordances and emotional experience: Socially engaging and disengaging emotions in Japan and the United States. Journal of Personality and Social Psychology, 91, 809-903. 
Kling, K. C., Ryff, C. D., \& Love, G. (2003). Exploring the influence of personality on depressive symptoms and self-esteem across a significant life transition. Journal of Personality and Social Psychology, 85, 922-932.

Kwan, V. S. Y., Bond, M. H., \& Singelis, T. M. (1997). Pancultural explanations for life satisfaction: Adding relationship harmony to self-esteem. Journal of Personality and Social Psychology, 73, 1038-1051.

Lee, M. R., Okazaki, S., \& Yoo, H. C. (2006). Frequency and intensity of social anxiety in Asian Americans and European Americans. Cultural Diversity \& Ethnic Minority Psychology, 12, 291-305.

Lucas, R. E., \& Fujita, F. (2000). Factors influencing the relation between extraversion and pleasant affect. Journal of Personality and Social Psychology, 79, 1039-1056.

Luhtanen, R., \& Crocker, J. (1992). A collective self-esteem scale: Self-evaluation of one's social identity. Personality and Social Psychology Bulletin, 18, 302318.

Lykken, D. T., \& Tellegen, A. (1996). Happiness is a stochastic phenomenon. Psychological Science, 7, 186-189.

MacIntosh, R. (1998). A confirmatory factor analysis of the affect balance scale in 38 nations: A research note. Social Psychology Quarterly, 61, 83-91.

MacKinnon, D. P., Lockwood, C. M., Hoffman, J. M., West, S. G., \& Sheets, V. (2002). A comparison of methods to test mediation and other intervening variable effects. Psychological Methods, 7, 83-104.

Markus, H. R. (1977). Self-schemata and processing information about the self. Journal of Personality and Social Psychology, 35, 63-78.

Markus, H. R., \& Kitayama, S. (1991). Culture and the self: Implications for cognition, emotion, and motivation. Psychological Review, 98, 224-253.

Markus, H. R., \& Kitayama, S. (1998). The cultural psychology of personality. Journal of Cross-Cultural Psychology, 29, 63-87.

Markus, H. R., Uchida, Y., Omoregie, H., Townsend, S. S. M., \& Kitayama, S. (2006). Going for the gold: Models of agency in Japanese and American contexts. Psychological Science, 17, 103-112.

Matsumoto, D. (2006a). Are cultural differences in emotion regulation mediated by personality traits? Journal of Cross-Cultural Psychology, 37, 421-437.

Matsumoto, D. (2006b). Culture and cultural worldviews: Do verbal descriptions of culture reflect anything other than verbal descriptions of culture? Culture and Psychology, 12, 33-62.

Matsumoto, D. (2007). Culture, context, and behavior. Journal of Personality, 75, 1285-1319.

Matsumoto, D., \& Yoo, S. H. (2006). Toward a new generation of cross-cultural research. Perspectives on Psychological Science, 1, 234-250.

McCrae, R. R. (2002). NEO-PI-R data from 36 cultures: Further intercultural comparisons. In R. R. McCrae \& J. Allik (Eds.), The Five-Factor Model of personality across cultures (pp. 105-125). New York: Kluwer Academic/Plenum Publishers.

McCrae, R. R., \& Costa, P. T. (1991). Adding Liebe und Arbeit: The full fivefactor model and well-being. Personality and Social Psychology Bulletin, 17, $227-232$. 
McCrae, R. R., \& Costa, P. T. (1999). A Five-Factor Theory of personality. In L. A. Pervin \& O. John (Eds.), Handbook of personality: Theory and research (2nd ed., pp. 139-153). New York: Guilford.

McCrae, R. R., \& Costa, P. T. (in press). The five-factor theory of personality. In O. John, R. W. Robins, \& L. A. Pervin (Eds.), Handbook of personality: Theory and research. New York: Guilford.

McCrae, R. R., Costa, P. T., del Pilar, G. H., Rolland, J.-P., \& Parker, W. D. (1998). Cross-cultural assessment of the five-factor model: The revised NEO Personality Inventory. Journal of Cross-Cultural Psychology, 29, 171188.

McCrae, R. R., Costa, P. T., Ostendorf, F., Angleitner, A., Hrebickova, M., Avia, M. D., et al. (2000). Nature over nurture: Temperament, personality, and life span development. Journal of Personality and Social Psychology, 78, 173186.

McCrae, R. R., Terracciano, A., Khoury, B., Nansubuga, F., Knezevic, G., Djuric Jocic, D., et al. (2005). Universal features of personality traits from the observer's perspective: Data from 50 cultures. Journal of Personality and Social Psychology, 88, 547-561.

McCrae, R. R., Terracciano, A., Leibovich, N. B., Schmidt, V., ShakespeareFinch, J., Neubauer, A., et al. (2005). Personality profiles of cultures: Aggregate personality traits. Journal of Personality and Social Psychology, 89, 407-425.

Norasakkunkit, V., \& Kalick, S. M. (2002). Culture, ethnicity, and emotional distress measures: The role of self-construal and self-enhancement. Journal of Cross-Cultural Psychology, 33, 56-70.

Oishi, S. (2002). The experiencing and remembering of well-being: A cross-cultural analysis. Personality and Social Psychology Bulletin, 28, 149-163.

Oishi, S., Diener, E., Scollon, C. N., \& Biswas-Diener, R. (2004). Cross-situational consistency of affective experiences across cultures. Journal of Personality and Social Psychology, 86, 460-472.

Oishi, S., Diener, E. F., Lucas, R. E., \& Suh, E. M. (1999). Cross-cultural variations in predictors of life satisfaction: Perspectives from needs and values. Personality and Social Psychology Bulletin, 25, 980-990.

Oishi, S., Wyer, R. S., \& Colcombe, S. J. (2000). Cultural variation in the use of current life satisfaction to predict the future. Journal of Personality and Social Psychology, 78, 434-445.

Okazaki, S. (1997). Sources of ethnic differences between Asian American and White American college students on measures of depression and anxiety. Journal of Abnormal Psychology, 106, 52-60.

Okazaki, S., \& Kallivayalil, D. (2002). Cultural norms and subjective disability as predictors of symptom reports among Asian Americans and White Americans. Journal of Cross-Cultural Psychology, 33, 482-491.

Okazaki, S., Liu, J. F., \& Longworth, S. L. (2002). Asian American-White American differences in expressions of social anxiety: A replication and extension. Cultural Diversity and Ethnic Minority Psychology, 8, 234-247.

Radloff, L. (1977). The CES-D scale: A self-report depression scale for research in the general population. Applied Psychological Measurement, 1, 385-401. 
Roberts, B. W., \& DelVecchio, W. F. (2000). The rank-order consistency of personality traits from childhood to old age: A quantitative review of longitudinal studies. Psychological Bulletin, 126, 3-25.

Roberts, B. W., Walton, K. E., \& Viechtbauer, W. (2006). Patterns of mean-level change in personality traits across the life course: A meta-analysis of longitudinal studies. Psychological Bulletin, 132 (1), 1-25..

Robins, R. W., Tracy, J. L., Trzesniewski, K., Potter, J., \& Gosling, S. D. (2001). Personality correlates of self-esteem. Journal of Research in Personality, 35, 463-482.

Rosenberg, M. (1965). Society and the adolescent self-image. Princeton, NJ: Princeton University Press.

Schimmack, U., Oishi, S., \& Furr, R. M. (2004). Personality and life satisfaction: A facet-level analysis. Personality and Social Psychology Bulletin, 30, 1062-1075.

Schimmack, U., Radhakrishnan, P., Oishi, S., \& Dzokoto, V. (2002). Culture, personality, and subjective well-being: Integrating process models of life satisfaction. Journal of Personality and Social Psychology, 82, 582-593.

Schrauger, J. S., Mariano, E., \& Walter, T. J. (1998). Depressive symptoms and accuracy in the prediction of future events. Personality and Social Psychology Bulletin, 24, 880-892.

Schwartz, T. (1978). Where is culture? Personality as the distributive locus of culture. In G. D. Spindler (Ed.), The making of psychological anthropology (pp. 419-441). Berkeley, CA: University of California Press.

Scollon, C. N., \& Diener, E. (2006). Love, work, and changes in Extraversion and Neuroticism over time. Journal of Personality and Social Psychology, 91, 11521165.

Sheldon, K. M., Elliot, A. J., Ryan, R. M., Chirkov, V. I., Kim, Y., Wu, C., et al. (2004). Self-concordance and subjective well-being in four cultures. Journal of Cross-Cultural Psychology, 35, 209-223.

Sheldon, K. M., Ryan, R. M., Rawsthorne, L. J., \& Ilardi, B. (1997). Trait self and true self: Cross-role variation in the Big-Five personality traits and its relationships with psychological authenticity and subjective well-being. Journal of Personality and Social Psychology, 73, 1380-1393.

Shimonaka, Y., Nakazato, K., Gondo, Y., \& Takayama, M. (1999). Revised NEO-Personality Inventory (NEO-PI-R) and NEO-Five-Factor Inventory (NEO-FFI) Manual for the Japanese version. Tokyo, Japan: Tokyo Shinri.

Singelis, T., Bond, M., Sharkey, W. F., \& Lai, C. S. Y. (1999). Unpackaging culture's influence on self-esteem and embarassability. Journal of CrossCultural Psychology, 30, 315-341.

Suh, E., Diener, E., Oishi, S., \& Triandis, H. C. (1998). The shifting basis of life satisfaction judgments across cultures: Emotions versus norms. Journal of Personality and Social Psychology, 74, 482-493.

Veenhoven, R. (1993). Happiness in nations: Subjective appreciation of life in 56 nations, 1946-1992. Rotterdam, The Netherlands: Erasmus University, Department of Social Sciences.

Veenhoven, R. (2000). Happiness in nations. World Database of Happiness, Erasmus University Rotterdam. Retrieved from http://worlddatabaseof happiness.eur.nl 
Watson, D., \& Clark, L. A. (1992). On traits and temperament: General and specific factors of emotional experience and their relation to the five factor model. Journal of Personality, 60, 441-476.

Watson, D., \& Friend, R. (1969). Measurement of social-evaluative anxiety. Journal of Consulting \& Clinical Psychology, 33, 448-457.

Weinstein, N. D. (1980). Unrealistic optimism about future life events. Journal of Personality and Social Psychology, 39, 806-820.

Weinstein, N. D. (1982). Unrealistic optimism about susceptibility to health problems. Journal of Behavioral Medicine, 5, 441-460.

Weinstein, N. D. (1987). Unrealistic optimism about susceptibility to health problems: Conclusions from a community-wide sample. Journal of Behavioral Medicine, 10, 481-498.

Wong, S. L. (2001). Depression level in inner-city Asian American adolescents: The contributions of cultural orientation and interpersonal relationships. Journal of Human Behavior in the Social Environment, 3, 49-64.

World Values Survey Group (1994). World values survey, 1981-1984 and 19901993. Ann Arbor, MI: Institute for Social Research.

Yamagata, S., Suzuki, A., Ando, J., Ono, Y., Kijima, N., Yoshimura, K., et al. (2006). Is the genetic structure of human personality universal? A cross-cultural twin study From North America, Europe, and Asia. Journal of Personality and Social Psychology, 90, 987-998.

Yamamoto, M., Matsui, Y., \& Yamanari, Y. (1982). Ninchi sareta jiko no shosokumen no kouzou [The structure of perceived aspects of self]. Japanese Journal of Educational Psychology, 30, 64-68.

Zung, W. W. (1965). A self-rating depression scale. Archives of General Psychiatry, 12, 63-70. 


\section{2}

